\title{
Giant Olfactory Groove Meningioma in Pregnancy
}

\author{
Tommy Rizky Hutagalung ${ }^{1}$, Faisal $^{1}$, Ridha Dharmajaya ${ }^{1}$ \\ ${ }^{1}$ Department of Neurosurgery, Universitas Sumatera Utara, Medan, Indonesia
}

\begin{abstract}
Introduction: Meningioma is slow growing neoplasm cells that comes from arachnoid cap most common benign intracranial tumours. Olfactory groove meningiomas (OGM) account for $8-13 \%$ of all intracranial meningiomas. Intracranial tumors on pregnancy is a rare event, with few reports.

Case Presentation: A 36-year-old- female (G11P9A1) 34 gestational week presented to the Adam Malik General Hospital with smelling disturbances for 6 months and lossing smelling sense in the past 1 month. Slowly progression of vision disturbances for 3 months without improvement in using glasses, progressive loss of vision in both eyes for the past 1 month. CT scan and MRI revealead a solid mass lesion, with $6.3 \times 4.2 \times 3.1$ $\mathrm{cm}$. It was a supratentorial in frontal region, olfactory groove mass. The Craniotomy tumor removal was performed in this patient.

Discussion: Meningiomas are mostly silent brain tumors with slow growth, however may get detected and mostly become symptomatic during pregnancy and luteal phase of menstrual cycle due to increase in size secondary to either water retention, enhanced vascularity or progesterones are possible etiologies. The majority of meningiomas express progesterone reseptor, which can be detected also by immunohistochemistry. In fact, tumour growth when progesterone concentrations are higher, shows the role of sex hormones in the mechanism. Regardless of the status of pregnancy, symptomatic and large meningiomas require surgical resection.

Conclusion: Changes of plasma concentration hormones during pregnancy and their effect on meningioma growth in the second and third trimester are crucial and critical. The management of brain lesions during pregnancy required professional collaboration between neurosurgeons, obstetricians and anesthesiologists.
\end{abstract}

Keywords: Meningioma, Olfactory Groove, Pregnancy, Neurooncology

\section{Introduction}

Meningioma is slow growing neoplasm cells that comes from arachnoid cap cells or meningothelial cells that cover the central nervous system, and most common benign intracranial tumours.[1][2][3] It gives neurological symptoms by compression of adjacent structures.[2] Incidence rate of 10\%-20\% of all intracranial neoplasms.[4] The highest incidence occurs in decades 5 to 6.[5] Female patient more likely to suffer from meningioma two or three times than males. During pregnancy and luteal phase in menstruation made meningioma become develop and grew faster, which a hypothesis phenomenon associated with a hormonal (endogenous and exogenous) pathway. The influence of female sex hormones are the growth and development of meningioma.[6]

Intracranial tumors on pregnancy is a rare event, with few reports of brain tumour associated with pregnancy. Only seven pregnant women with primary brain tumors were 
found among 126.413 pregnancies over 13 years, and two of them had meningiomas.[7] The underlying mechanism for this growth may consist of elevated serum estrogen and progesterone levels in pregnant patients. [4] Dramatic growth of meningiomas is occasionally encountered during pregnancy, and may exhibit accelerated growth during the second half of pregnancy.[8] As a result, rapid changes in meningioma size occur during pregnancy, putting both the mother and fetus at risk. Regardless of the status of pregnancy, symptomatic and large meningiomas require surgical resection. The management of brain lesions diagnosed during pregnancy is challenging to both neurosurgeons and obstetricians.

\section{Case Report}

A 36-year-old female grande-multigravida pregnancy (G11P9A1) 34 gestational week come to Haji Adam Malik General Hospital, with chief complain of smelling disturbances for 6 months and lossing smelling sense in the past 1 month. Slowly progression of vision disturbances for 3 months without improvement in using glasses, progressive loss of vision in both eyes for the past 1 month. History of headache since 1 year ago. Without history of hormonal contraception. On physical examination patient was alert with neurological deficit bilateral anosmia and blindness in both eyes (Visus ODS : No light perception). Billateral papil atrophy was found in funduscopy examination. Brain computed tomography (CT) scan and magnetic resonance imaging (MRI) revealead a solid extra-axial mass lesion with contrast enhancement, with size $6.3 \times 4.2 \times 3.1 \mathrm{~cm}$ (figure 1 and figure 2). The mass origin was a supratentorial frontal base region, olfactory groove mass, extended to upper segment of frontal lobe.
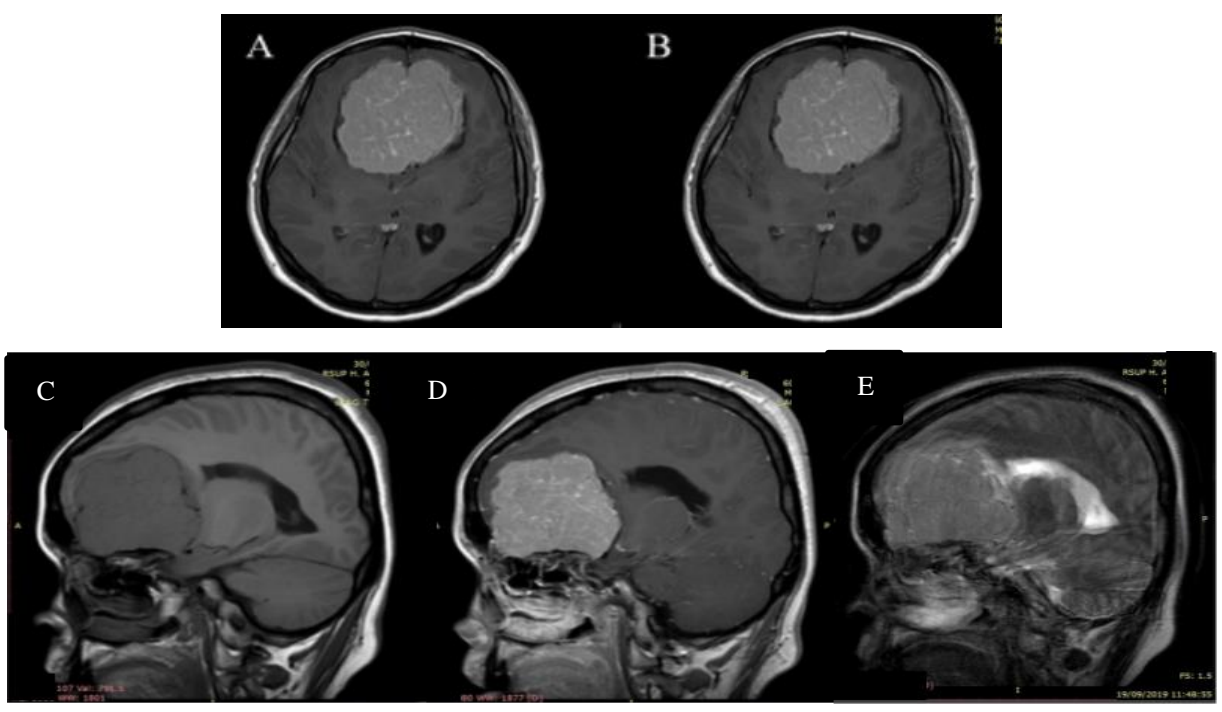

Figure 1. (A) MRI Brain Contrast Axial T1 (B) Axial T1 + contrast (C) MRI Brain Contrast Sagital T1 (D) Sagital T1 + contrast (E) Sagital T2 


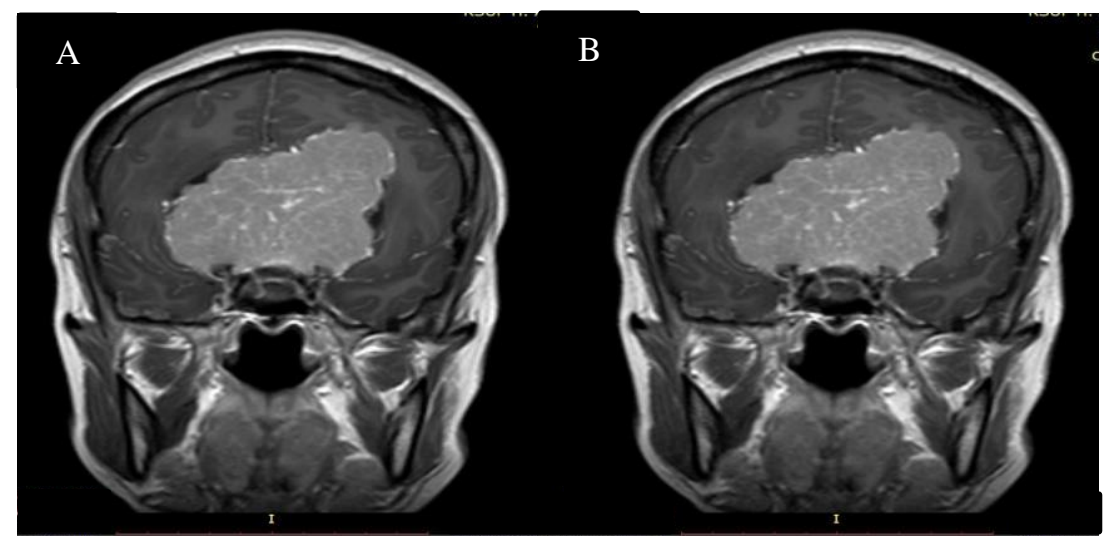

Figure 2. MRI Brain Contrast (A) Coronal T1 (B) Coronal T1 + contrast

Based on ultrasound examination of pregnancy, fetus was in good condition, with a gestational age of 34-35 weeks (figure 3). Considerations from Obgyn department, if tumor removal surgery is to be performed, consider it to be done when the fetus is viable, joint operation with section caesaria procedure. As the condition of both patient and fetus, it was decided after consultation along with obgyn department to underwent tumour removal under general anasthesia with rapid sequence intubation.

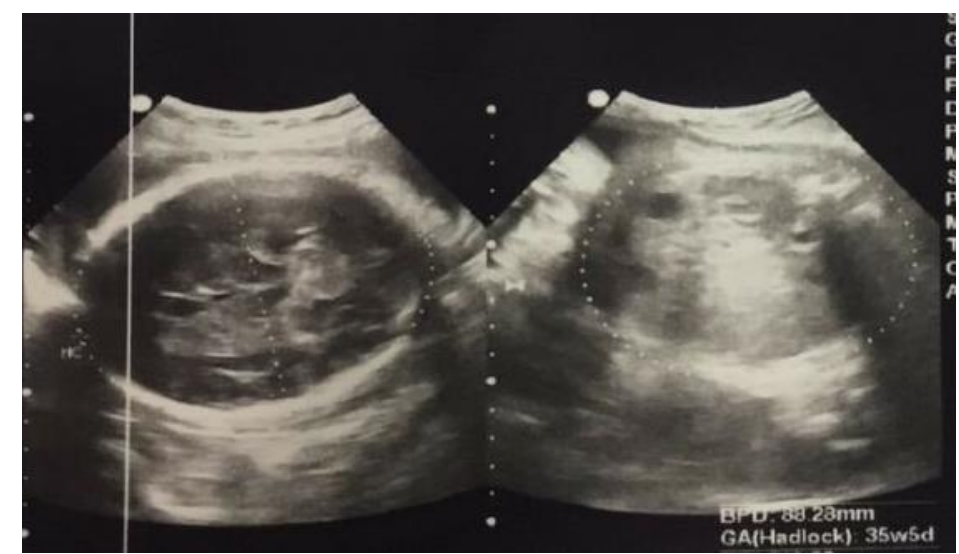

Figure 3. Pregnancy Ultrasound

The patient underwent surgical intervention and perfomed in the supine position. The lesion was approach by a frontal craniotomy. A complete resection could be achieved by 8 burr hole, and free bone flap 15 × $8 \mathrm{~cm}$, the dura was opened, sinus sagitalis inferior ligasion and durotomy. Subarachnoid disection, devascularization and tumor debulking internally. The tumor was found to be firm, grey, tender, suctionable without spontaneus bleeding. No intraoperative complications occured, and the tumor was totally resected, with bleeding control before closure (figure 4). 


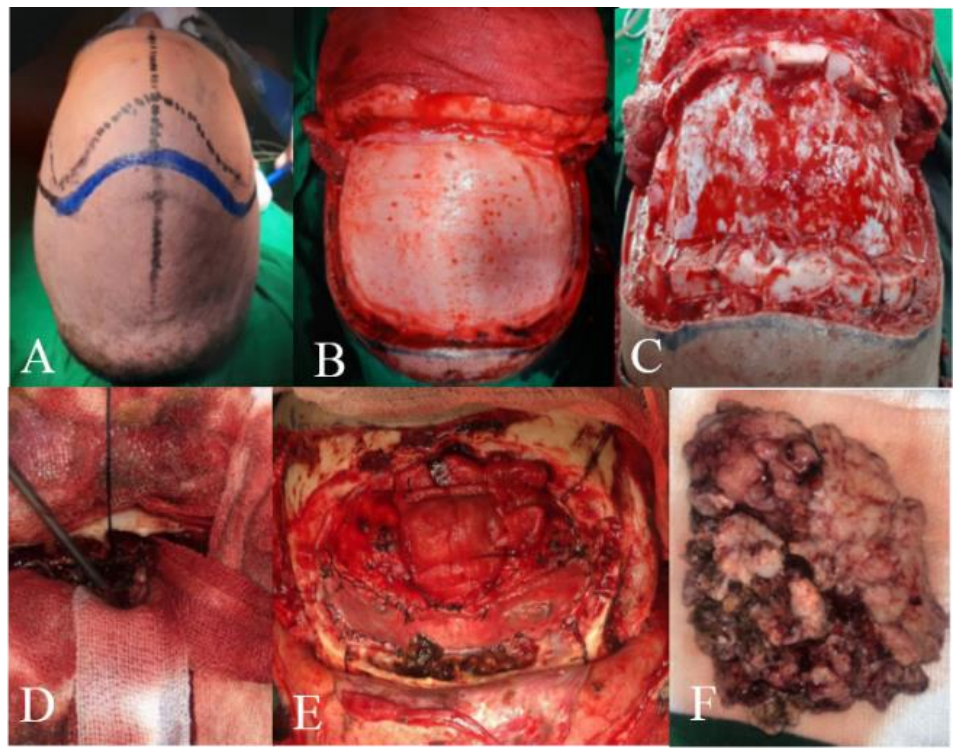

Figure 4. Intraoperative (A) Marking incision (B) Frontal bone (C) Duramater exposure (D) Sinus sagitalis ligation (E) After tumor resection; (F) Tumor mass

\section{Discussion}

Meningiomas account for approximately $15 \%$ of all intracranial neoplasms. Meningiomas are mostly silent brain tumors with slow growth, however may get detected and mostly become symptomatic during pregnancy and luteal phase of menstrual cycle due to increase in size secondary to either water retention, enhanced vascularity or progesterones are possible etiologies. [9][10] A cohort study, showed relationship between progesterone receptor status and the biological behavior of tumors. Patients with progesterone-positive tumors revealed decreased recurrence rates after tumor resection. [10] [11]

Meningiomas rarely occur during pregnancy, estimated 5.6 cases out of 100,000 pregnancies. Low incidence of meningioma because of fertility range is around 15-45 years and meningioma which have the highest incidence between the ages of 60 and 70 years. One important aspect of meningioma in pregnancy is the rapid growth with life-threatening complications. [12] [13]

During pregnancy, FSH and LH and prolactin are low due to negative feedback mechanisms that affect the anterior hypophysis. FSH, LH and hCG glycoprotein in vitro study can inhibit tumor cell proliferation; in contrast, human placental lactogen (hPL) and prolactin (PRL) can stimulate tumor growth. The second and third trimester of pregnancy is very important and critical. [14][15] Estrogen receptors (ER) are not expressed in most meningiomas. The role of progesterone receptors (PR) where an inverse relationship between 
protein expression and tumor.[15] While the rate of mitosis increases with a higher grade, meningiomas in pregnancy are mainly low grade. Therefore, it is questionable whether rapid tumor growth is related to cell proliferation induced by progesterone or not.[16] The majority of meningiomas express PR, which can be detected also by immunohistochemistry. In fact, tumour growth when progesterone concentrations are higher, shows the role of sex hormones in the mechanism. [16] [17]

Tumors compress the surrounding structures can lead to most frequent symptoms such as headache, dizziness, focal lesions and epilepsy. The skull base is a common localization of meningiomas, progressive growth during pregnancy often results in visual impairment. [17] [18] Optic nerve compression causes reduced venous return, resulting blurry and papillary oedem on funduscopy. Oculomotor nerve compression lead to functional deficits of intraocular muscles, anisocoria, pupillary dilatation and absence of light reactions. Surgical resection is still the main curative treatment of meningioma, and the rate of peritumoral brain edema is also decreases after successful neurosurgical intervention. Brain surgery during pregnancy is very risky for mother and child, so continuous intraoperative monitoring as well as professional collaboration between brain surgeons, obstetricians and anesthesiologists can not be avoided.[19] In this case, general anaesthesia can be safe in pregnant patients with intracranial tumours. Tracheal intubation is very important as it allows maternal hyperventilation thereby controlling raised intracranial pressure. [19] [20]

\section{Conclusion}

Giant gestational meningioma or meningioma in pregnancy are rarely occur, the underlying mechanism for this growth may consist of elevated serum estrogen and progesterone levels. As a result, rapid changes in meningioma size occur during pregnancy, putting both the mother and fetus at risk. Regardless of the status of pregnancy, symptomatic and large meningiomas require surgical resection. The management of brain lesions during pregnancy required professional collaboration between neurosurgeons, obstetricians and anesthesiologists. 


\section{References}

[1]. Meningiomas in Pregnancy: A Clinicopathologic Study of 17 Cases Eriks A. Lusis, Bernd W. Scheithauer, Anthony T. Yachnis, Bernhard R. Fischer, Michael R. Chicoine, Werner Paulus, Arie Perry, Department of Neurosurgery, Washington University School of Medicine, St. Louis, Missouri. Neurosurgery 71:951-961, 2012

[2]. Carlberg M, Söderqvist F, Hansson Mild K, Hardell L. Meningioma patients diagnosed 2007-2009 and the association with use of mobile and cordless phones: A case-control study. Environ Heal A Glob Access Sci Source. 2013;

[3]. Jiang XB, Ke C, Han ZA, Lin SH, Mou YG, Luo RZ, et al. Intraparenchymal papillary meningioma of brainstem: Case report and literature review. World J Surg Oncol. 2012 ;

[4]. Kerschbaumer J, Freyschlag CF, Stockhammer G, Taucher S, Maier H, Thomé C, et al. Hormone-dependent shrinkage of a sphenoid wing meningioma after pregnancy: Case report. J Neurosurg. 2016;

[5]. Tandon Prakash N, Ramamurthi R, Jain N Pradeep K, Jain V. Chapter-167 Tentorial Meningiomas. In: Ramamurthi and Tandons Manual of Neurosurgery. 2014.

[6]. Wahyuhadi J, Heryani D, Basuki H. Risk of meningioma associated with exposure of hormonal contraception. A case control study. Maj Obstet Ginekol. 2018;

[7]. Shitara S, Nitta N, Fukami T, Nozaki K. Tuberculum sellae meningioma causing progressive visual impairment during pregnancy -case report-. Neurol Med Chir (Tokyo). 2012;

[8]. Kurdoglu Z, Cetin O, Gulsen I, Dirik D, Bulut MD, Dumont AS. Intracranial meningioma diagnosed during pregnancy caused maternal death. Case Rep Med. 2014;

[9]. Alver I, Abuzayed B, Kafadar AM, Rezai SM, Sanus GZ, Akar Z. Primary fourth ventricular meningioma: case report and review of the literature. Turk Neurosurg. 2010 ;

[10]. Ravi AK, Sachdeva P, Gandhi G, Rana A. Pregnancy with Meningioma: Report of Two Rare Cases. J Case Reports. 2017;

[11]. Mukherjee S, Ghosh SN, Chatterjee U, Chatterjee S. Detection of progesterone receptor and the correlation with Ki-67 labeling index in meningiomas. Neurol India. 2011;

[12]. Dumitrescu BC, Tataranu LG, Gorgan MR. Pregnant woman with an intracranial meningioma - case report and review of the literature. Rom Neurosurg. 2015; 
[13]. Hortobágyi T, Bencze J, Murnyák B, Kouhsari MC, Bognár L, Marko-Varga G. Pathophysiology of meningioma growth in pregnancy. Open Medicine (Poland). 2017.

[14]. Al-Chalabi M, Alsalman I. Physiology, Prolactin. StatPearls. 2019.

[15]. Csonka T, Murnyák B, Szepesi R, Bencze J, Bognár L, Klekner Á, et al. Assessment of candidate immunohistochemical prognostic markers of meningioma recurrence. Folia Neuropathol. 2016;

[16]. Qi ZY, Shao C, Huang YL, Hui GZ, Zhou YX, Wang Z. Reproductive and exogenous hormone factors in relation to risk of meningioma in women: A meta-analysis. PLoS One. 2013;

[17]. Wiemels J, Wrensch M, Claus EB. Epidemiology and etiology of meningioma. Journal of Neuro-Oncology. 2010.

[18]. Lusis EA, Scheithauer BW, Yachnis AT, Fischer BR, Chicoine MR, Paulus W, et al. Meningiomas in pregnancy: A clinicopathologic study of 17 cases. Neurosurgery. 2012;

[19]. Sahu S, Lata I, Gupta D. Management of pregnant female with meningioma for craniotomy. J Neurosci Rural Pract. 2010;

[20]. Farag E, Abd-Elsayed AA, Díaz-Gómez J, Barnett GH, Kurz A, Inton-Santos M, et al. A case series discussing the anaesthetic management of pregnant patients with brain tumours. F1000Research. 2013; 